\title{
NOTAS SOBRE TRES NOVELAS MEXICANAS
}

\author{
P O R \\ Josérojas GARCIDUEÑA
}

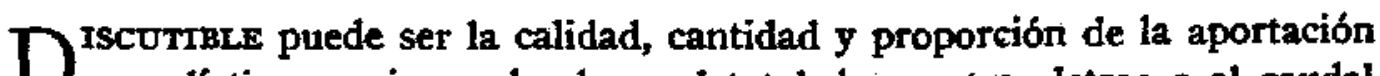
novelística mexicana de ahora al total de nuestras letras o al caudal de las literaturas de lengua castellana, que todo depende de la profundidad o amplitud que alcance a enfocar la lente, pero como quiera y cualquiera que sea el resultado, lo indudable es la necesidad de proceder con mesura $y$ ponderación si se quiere obtener alguna conclusión válida y no meras apreciaciones infundadas y vacuas que sólo sirvan para desorientar al que investiga y para enturbiar las aguas, cuando justamente se busca el relieve de sus fondos y las riquezas vitales de su seno.

Quierg esto decir que, a más de las notas bibliográficas que al aparecer un nuevo libro suelen publicarse en diarios y revistas, deben también hacerse extractos, valoraciones $y$ análisis, acaso menos informativos pero más rigurosos en el examen específicamente literario, de. modo que las obras a que se refieran queden calificadas y situadas en el lugar que les corresponde y sepa el lector a qué atenerse en cuanto al valor literario y cultural de aquéllas. 
Porque actualmente ofrecen en México notable contraste los conocimientos históricos, teóricos y técnicos de las artes plásticas y el saber paralelo en las literarias; fácil es comprobarlo: estos mismos Anales y el trabajo de este Instituto de Investigaciones Estéticas asi lo atestiguan. Constantemente vemos publicaciones varias, del artículo en un diario al libro erudito, ilustrado y lujoso, que versan sobre pintores contemporáneos, estudios técnicos de nuestra pintura, manifestaciones de culturas precolombinas, etc., $y$, en cambio, lo que se ha escrito en el terreno de la historia literaria es poco y con frecuencia no corresponde a una tabla de valores que pueda considerarse actual, y respecto a lá técnica y a la teoría literatis 108 ttibajos ton aúli mbs raros, sunque por fortuna un rayo de esperanza alienta puesto en el esfuerzo tan vigoroso y elaborado como el de don Alfonso Reyes para construir una teoría literaria hasta hoy inexistente, así como en los ensayos tan apreciables de José Luis Martínez.

La conciencia de que es ya urgente la necesidad de emprender, asi sea parcialmente, investigaciones en el campo de nuestra literatura me ha traído a redactar estas notas sobre tres novelas mexicanas de reciente publicación, no tanto para informar de ellas a los posibles lectores, sino más bien, como adelante se irá especificando, para señalar los principales valores (en todos sentidos, inclusive negativos) que por una $\mathbf{u}$ otra parte puedan precisar corrientes, señalar metas o perfilar caracteres de nuestras detras. Asi pues, he pretendido simplemente dar cornienzo (confiando en proseguir posteriormente) a una construcción que es necesario hater, allegando materiakes, curyo valor ni yo ni madie puede aún precicar $\rightarrow$ j lo mismo da que senn luego desperdiciados o resulten importantes-m, porque su función posterior dependert́ de bolocación que encucntren en el editicio a que sirvan.

El viejo principio de "nobleza obliga", no por sobado y repetido deja de ser cierto. Cuando se lleva un nombte ilustre 0 , al menos, muy sefalado, los actos cobran tina importancia diferente a la que protiera atributitseles en personas sin renombre, simples midades de la colectividad en que viven.

Tal es el caso del doctor Atuela : st fama if oblige en modos mas estrictos que al excritor novel. Otro es el problema de st a reannbre de Azuela como novelista es fustifleado o wo $y$ por ahora no deseo bocat ese tema, pero es indudable que tal renombre existe y ud circunatancia 
carga sobre don Mariano Arnela un fardo de responsabilidad muy consi* derable, attmettado todavía más por el reconocitniento oficial de sus méritos literarios, premiados con el sillón que ocupa en El Colegio Nacional.

Son esas condiciones las que me han inducido a tratar de su obra última o penúltima, que vió la luz publicada oficialmente por el ilus tre Colegio, 1 ediciones de obras de sus miembros. En otras circunstancias no me sentiria obligado a las anotaciones que siguen, pero, concurriendo ellas y habiéndome yo propuesto en estas notas presentar los ejemplos más significativos de la novelistica mexicana en este momento, no podía desdeñar el referirme al doctor Azuela y a esa obra suya que cae en el ámbito reciente que he delimitado para enfocar estas notas.

El tema es la vida de una muchacha perteneciente por gu origen a la baja clase media de Moreliz, de acusada vanidad y defectwosamente educada por su padre, que inicia sus estudios en su ciudad natal y viene luego a México decidida a conquistar un puesto relevante en la esfera universitaria de la capital; sufre reveses, menosprecios y fracasos, regresa a Morelia y, prescindiendo de su propósito, decide quedarse en su casa y termina formalizando an noviazgo con m antiguo pretendiente $y$ compañero suyo de tiempo atrás.

Tal asunto no es mury original y tampoco puede considerarse tema vulgar, pero aunque fuera verdad cualquiera de los cos casos, el resultado sería el mismo, pues el asunto de una obra literaria, en if y por sí, suele tener escasa importancia para ed juicio último $y$ definitivo que la obra merexca. Porque en las letras ocurre lo mismo que en la pintura y que en todas las artes: lo más importante no es, por lo común, el tema, sino la manera de tratarlo. El tema puede ser tuna vasija y tres frutas sobre tiria mesa, pero hay mucha distancia entre un bodegón del siglo xvirl y una naturaleza muerta de Cézanne; la mujer es tema constante y eterno, mas no por ello pbdrán confundirse la Varidad de Memlindk, la Grande Baigneuse de Ingres, la Majo deswuda te Goya o La Grande Danseuse d'Avignon de $\mathrm{f}$ casso. Lo mismo paede decirse de la mfisich, de ha escultura, etcétera, e igual ocurre en literatura. El tema de los celos ha inspirado miles Ae novelitas cursis, pero tambitn a Shakespeare, y con el tema de la revolución mexicara se han hecho tres 0 cuatro obras buetuas - Los de Abajo, El Aguile y la Sariente, El Gesticulador y alguna más-, pero

1 Mareano Azterna. Lo mujet domoda. Noteĺa por ... Mientbro fundador de El Colegio Nacional. Ed de El Colegio Nacional. Nexico, D. F., 1946. 
luego ha servido de pretexto a un río de abominables relatos que han hecho de nuestra literatura actual lo mismo que con nuestro lamentable y desprestigiado cine: un interminable desfile de títeres a pie y a caballo, con sombreros de petate, disparando balazos y prorrumpiendo en frases más o menos soeces para darle al engendro tinte de folklore.

Sobre el tema susodicho, La mujer domada presenta una estructura claramente dividida en tres partes: los antecedentes de, la protagonista hasta el momento de su llegada a México, su vida en la capital y su regreso a Morelia. Ia primera parte se llena a base de largas narraciones apenas zurcidas con breves diálogos de valor muy desigual, pero siempre ahogados por el relato, que se lleva la mayor parte dejando a la acción postergada. La estructura de la parte segunda es extremadamente pobre: toda la acción gira repitiendo dos o tres situaciones sin vigor ni atractivo, que tampoco llegan a impresionar por su insistencia monótona, efecto tan bien logrado, por ejemplo, en obras como La Aldea de Bunin y otras semejantes. La tercera parte, el regreso a Morelia, resulta menos pobre, más rápida y más fresca. El final es lamentable por su barato sentimentalismo y su vulgaridad. No es, pues, la estructura o composición lo que puede salvar esta novela, antes debe considerarse en ella dicho elemento como deficiente, pobre y sin mérito.

La novela se desarrolla en dos ambientes: en Morelia y en México; el primero muy bien descrito; sentido $y$ vivido, aunque suele pecar de toques de "pintoresquismo" de gusto dudoso, pero también con chispazos que en una frase sugieren tonalidades de la vida social o psicológica muy bien puestos y muy importantes. El ambiente en que se mueve la protagonista en México no puede ser literariamente peor: falso, arbitrario, sin fuerza, paupérrimo.

$\mathrm{Ni}$ las'ideas ni el estilo son elementos que puedan salvar esta obra de Azuela. La forma es mediocre: a veces incorrecta, pero en ocasiones tiene aciertos notables; algunas descripciones son en verdad muy buenas, y otro tanto debe afirmarse de algunos diảlogos entre personajes y en ambiente de provincia, en contraste con los diálogos entre estudiantes y en el pretendido medio universitario de México, que son frios, artificiosos y huecos.

De todos, el más importante y mejor tratado de los elementos de la obra en cuestión es, sin duda, el que comprende los personajes.

Toda la obra está construida sobre un personaje que le sirve de eje: tal es la protagonista, Serafina; sus características son una recia voluntad, 
audacia y decisión por una parte, y por otra, un orgullo casi siempre degenerado en vanidad; así la muestra el libro implícitamente y explícitamente la describe el autor por boca del estudiante Mateo Rivero, que dice de Serafina: "Educación inadecurada, facultades mediocres, vanidad desorbitada y como resultado aquella vana garrulería y aquel enfásis pedante que le enajenaba la simpatía de los mejores..." (p. 65.) Ambiciosa, Serafina trata de superar su humilde origen, instigada primero por su padre y luego por cuenta propia; el autor la presenta como una muchacha bonita, físicamente atractiva. Es un personaje con algunas fallas notables, sobre todo en ciertas situaciones de su vida universitaria en México, pero en general bien construído y muy digno de ser base y protagonista de una novela.

Tomás, padre de Serafina, es también personaje bien estructurado, lógico, entendiendo por tal no una lógica "objetiva" del personaje, sino la lógica "interna" de coordinación entre sus diversas reacciones y situaciones con sus ideas, educación, etc., es un tipo ambicioso e inculto; el autor logra combinar bien las cualidades y defectos de este personaje con su actuación en la obra; lástima que para mostrarlo recurra el doctor Azuela excesivamente a la narración, debilitando la vida que podria haber conseguido con más amplitud por el diálogo y la acción; desgraciadamente, también, el autor cayó en algunos lapsus, así cuando, porque su hija gasta en trapos, Tomás repentinamente se presenta "sollozando" y el autor, en su irrefrenado descenso, nos llega a decir que estaba Tomás "todavia con lagrimones en las mejillas", situación absurda y rebosante de mal gusto, dado el tipo y el motivo de que se trata.

Otro error semejante, en cuanto a su torpeza, es la forma en que Azuela hace reaccionar a Serafina al enterarse de la muerte de su-madre (pp. 153-154), en forma indeciblemente ilógica y cuando el autor debió aprovecharla para ahondar en el carácter de la protagonista, pues para eso sirven muy particularmente las grandes conmociones anímicas y los momentos trácicos de una obra, que tanto ayudạn a desnudar la psicología del personaje que los sufre.

Aunque hay otros dos o tres personajes fundamentales para el desenvolvimiento de la trama, son casi todos secundarios, sin relieve psicológico y sin atractivo; acaso podría exceptuarse Felisa, chica neurótica y desequilibrada que aparece muy viriente en varias situaciones, todas ellas coherentes e interesantes; es decir, se trata de un personaje bien construído en su calidad de segundo plano que estructuralmente le corresponde. 
Novela, pues, con muchos y graves defectos; con aciertos en sus personajes $y$ en algunos momentos de su acción y de su ambiente pero, en resumen, el balance fimal es sin duda por completo desfavarable.

Ciertamente reconozco que esta obra ye está construída más en novela que otras anteriores del nismo autor, que no pasan de ser relatos, pero es preciso también decir que es una mala novela, por lo cual es doblemente Jamentable que haya aparecido pablicada ostentosamente por E1 Colegio Nacional, aunque bien sabido es ctuán heterogéneamente se ha integrado ese olimpo cultural de México.

Eirén Hernández ea duexio de una de las prosas más delicadas que puede ofrecer la literatura de México; su vida, su particular sistema de trabajo, su personalidad toda, tienen un sello de originalidad que no puede menos de reflejarse en su obra contenida en tres o cuatro libros, seguramente mucho menos difundidos de lo que su espléndida calidad merece; unos magníficos cuentos y un tomo de buenos poemas era lo conocido de este autor, que ahora ha publicado una novela, en pequeño formato muy en consonancia con su texto y con su autor. 1

Se inicia con la autopresentación del protagonista y desde luego sugiere un estado psicológico indeciso, vago, crepuscular; hay un aire humilde $y$ una leve amargura que, una que otra vez, deja transparentar muy leve matiz de strave y lejana ironia.

También desde sus comienzos la obra se da en una tierna poesia $y$, sin dejar de fluir, surge la metáfora, la imagen nuteva y original, riunca en modo naturalista, antes siempre en tono poético, como puede verse:

"De mi, pues pasé to que pasé, y tengo noticias mias, sé quẹ renazco y que si en dias he sido, o no, hombre mortal, ahora cosa alguna bastará a deshacerme, cosa alguna conseguirá arrancarme como a un suspiro, pez o perla, del mar de la existencia ; pero de la luz del mundo, no sé si viene o va. (pp. 14-15.)

"Me halláis convaleciente. Esta vez empecé a abrir los ojos, hace - dentro de este ambiente sin tiempo que es como un marzo sin aire, océano sin ondas, vena sin pulso, u órbita donde no se

1 Prrke HernAnpiz. Cerrasón sabre Nicomaco. Ficción harto dotiente. Portada y vifietis del awor. Mostion, 1946. 
conoce el parpadeo m momento tan largo, como los dos brazos de una estatua, entreabiertos." (p. 15.)

Poco a poco precisa una sensación y un ambiente de incorporeidad, de colores firmes y formas claras, pero de cosas incorpóreas, y acaso inexistentes; se refiere al agua y sus reflejos y así es para él la inteligencia y él (Nicomaco) es el "bobo del agua", La apariencia de las cosas en el agua es superior a las cosas mismas, por eso "el Paraiso era mucha agua ... Y Dios mismo, ahí se complacía infinitamente". Los ojos de la mujer amada "fueron comp inmortales yalles inundados de un agua que trasparecía y se mostraba como eterna . . . sus efímeros ojos fueron como perennes prados tempraneros, anegados, como ondeantes valles bajo un vidrio simplísimo, cual todo un paraíso visto más allá de una cortina de agua desplegada". (p. 22.)

Asi, toda esta parte primera funciona en la obra sirviendo para la presentación del protagonista, pero, además de su papel en la estructura del libro, esas quince páginas iniciales son de muy acusado tirismo hasta el grado en que sorprende su innegable utilidad para la comprensión interna de una obra épica.

La segunda parte es el relato de los sucesos, trama de la novela. Al principio adopta una forma de narración humoristica, trivial, haciendo chistes fáciles y vulgares, pero, cuando parece que esas páginos van a contener y a contarnos lances pintoreseos para provocar risa o sonrisa ingenua, el lector no puede menos de semtir algún desconcierto cuando, inesperadamente, surge la primera pincelada de irrelidad al empezar el segundo tercio del libro, irrealidad — ¿sobrerrealidad?- que por el resto de k novela seguirá alternándose, combinándose con 10 normal y ordinario, en un juegortheno de soltura y agilidad.

Acaso una de las principales caracteristicas de esta "ficción" sea el uso de eleméntos cromáticos, a veces con intención de producir efecto psicológico eff el lector y que en otras ocasiones aparecen súbitamente, como si al pasar conversando por las calles de repente nos asomáramos a una ventana tras de la cual hubiera un cuadro a un mosaico o un vitral, que eso sugieren algunos pasajes de esta novela; véase si no esta breve descripción que hace del resultado que dió el que Nicomaco, el protagonista, dejara escapar de sus manos el paquete del encargo, al descender en un prado de la Alameda, y diepermarse los objetos que contenia: 
"¡Ay negra, negra suerte! Qué esquiliano espectáculo recogieron mis ojos; tal como si el campeón de los aparadoristas los hubiera dispuesto, así quedaron. Hubierais visto el pliego guinda, desplegado, aletear airoso sobre un macizo de amapolas amarillas; el medio litro de lámina cromada, con su asa naranja, de pie sobre el único remiendo negro de un pavimento de mosaicos marfilinos, $y$ en medio de los tres dobledecimetros en posición de flechas encargadas de encaminar los ojos hacia él, y un mano a mano de guantes escarlata con violetas, brillando tomo brasas sobre las que soplara un fuelle, encima de, precisamente, el césped más tupido y verde que se podía encontrar en cien metros a la redonda..." (pp. 37-38.)

¿Qué es sino un cuadro, un delicioso cuadro? Por sus elementos plásticos: las flores, el recipiente de metal, las reglas de madera, los guantes, etcétera, y por su composición es todo ello un cuadro precioso (acaso hasta preciosista) que sugiere algo de Dalí, atunque de mayor colorido, tanto que hace recordar un Juan Miró y a cierto Carlos Mérida.

No quiero hacer consideraciones de mayor alcance sobre el uso y función de la riqueza y vivacidad del color en la novela mexicana; carezco del vasto cuadro comparativo que el tema requiere y sin el cual no creo se deban aventurar hipótesis que luego podrian resultar inconsistentes; apunto solamente el dato de los elementos plásticos en la novela de Efrén Hernández, seguro de que serán recogidos más tarđe por cualquiera de los que ya nos preocupamos por escudriñar la novelística mexicana con algo más de rigor que nuestros predecesores los románticos y retóricos del siglo pasado.

Toda esta segunda parte del libro desenvuelve una acción que sólo muy lejanamente tiene que ver con la que aparenta ser la principal en la trama; pero ¿ hay de verdad una trama en esta "ficción"? Muchas veces parece que no existe, que no hay núcleo ni eje y que las extrañas situaciones se suceden por puro capricho, mas apenas se evite la distracción que produce lo raro del ambiente, se verá que la trama existe y está presente en toda la extensión del libro, pero no son las situaciones las que la descubren sino hasta las dos últimas partes; lo que a mi juicio revela y constituye el hilo que engarza las tan diversas cuentas es el estado anímico del protagonista, esa continuada angustia, esa agonia de llanto reprimido, de sollozo que es nudo en la garganta, con que el triste Nicomaco cruza por todas, absolutamente por todas las páginas de su breve existencia. 
Y es esa misma angustia la que produce arranques líricos de extremada finura y tierno matiz que, sin romper la unidad de la narración, a veces casi se sienten como fragmentarios poemas incrustados entre guiones de acción. ¿Qué otra cosa son trozos como estos?:

"Menor es la distancia que va desde la tierra resquebrajada y seca, hasta el unido ojo reluciente en humor clarísimo y sereno; que desde las lentas y cargadas horas, hasta el constante espejo que las aúna todas.

"Es claro, a más inteligencia corresponde más asombro, no menos misterio; pero, entre todos, aquel que más se abisma, es el que pesa menos." (P. 58.) fuente:

$\mathrm{O}$ estos otros, también en la muda contemplación del agua de una

"El agta deseada es, a un sediento, lo mismo que a cualquier otro sediento: hombre, camello o pájaro; pero la otra, en que yo me extasiaba, esa vivía. Ella y yo lo sabemos; estuvimos tan juntos, y callados, y a solas.

"En ella obscurecía. El delicado abismo de su carne incolora, recogíase en ese ahondamiento que engrandece el espacio, cuando aliviado de la alucinante intrusión del sol, consigue ensimismarse, y tornarse, por ende, más puro y más sincero. Así crecen los ojos a la virtud del acto con que el entendimiento entiende. Así, las soledades, hácense sin fondo cuando el silencio cunde. Entonces, las estrellas despiertan, las voces se matizan, y el universo mundo es como amante comprobando, extrañado, que el lloro tiene axigar, en el instante en que los ojos que ama sostienen su mirada." (Pp. 59-60.)

Un ambiente irreal, entre sueño y delirio que recuerda (sin ninguna similitud) a Franz Kafka; algunas páginas en que las formas y los colores, a pesar de las palabras, funcionan en manera más puramente plástica que literaria; varios párrafos de acusado lírismo sin mengua de la secuencia normal, tales son los caracteres de este último libro de Efrén Hernández que me han movido a mencionarlo aquí, pues sin duda es importante anotar la aparición de esos elementos, nuevos en nuestras letras, que 
Efrén Hernatidez ha sabido manejar con la delicadeza y la finura caracteristicas de su precioso estilo. Cabe adernás advertir que ese material de fondo ha sido logrado en forma absolutamente auténtica, es decir, que el autor no trató de copiar ni seguir alguno de los varios ejemplos que padieran darse, sino que, partiendo de unos cuantos esbozos: contemplación del agua de la fuente, los brillantes objetos dispersos en el prado y la breve trama en torno del canguro, ocurrencias todas de procedencia no consciente, afloradas a la conciencia de súbito y anotadas luego partiendo de esos trazos, casi inconexos, empezó a construtr, ya en elaboración consciente, el resto de la obra, arnque, como es natural, empleando otras muchas aportaciones no racionales sino imaginadas por procesos stubconscientes.

Todo eso, a mi juicio, tiene doble importancia: la de usar una técnica hasta hoy desusada en la composición de novelas mexicanas $y$, por otra, el ampliar considerablemente el ámbito y el sentido de lo real superando el naturalismo tradicional para llevario a una más compleja integración con elementos humanos de mayor profundidad.

Al filo del agua ${ }^{1}$ es una novela auténtica y es una buena novela. Acaso tal afirmación parezca impertinencia porque puede pensarse, con buen juicio, que mejor estaria como conclusión previamente demostrada y no frase inicial de una nota crítica; pero el sentido que lleva no es de juicio a priori, sino más bien ubicación necesaria y casl enunçlado del tema que los siguientes párrafos van a tratar: "novela auțéntica" quiere decir que el término genérico "novela" es aquí correcto en su aplicación más estricta, en contra de lo que comúnmente ocurre, que se llama novelas a obras que no lo son y que mejor debieran denominarse relatos, narraciones y a veces hasta ensayos, $y$ digo "buena novela" porque es también común y ordinario que los críticos, por motivos de diversa índole, califiquen el libro a que se refieren como "uno dẹ los mejores" en su género hasta entonces, todo lo cual es demasiado vago $y$, en puridad, falto de valor en el doble sentido de que, respecto al crítico, elude el compromiso de un juício más concreto $y$, respecto al objeto, sugiere un elogio comparativo sin precisar el valor de que se parte.

1 Agustin YAkez. Al filo dal agua. Novela. Ilustraciones de Julio Prieto. EA. Porrúa, S. A. México, 1947. 
Pero afirmar que tal novela es buena no es decir que sea perfecta, y por eso, si adelante se encontrarán censuras y elogios, tampoco es que pretenda suavizar las primeras ni atenuas los segundos para quedar en un aparente equilibrio de cortesín y neutral comodidad; es que, a pesar de que toda obra literaria constituye en si misma una unidad, sus partes o elementos no guardan siempre el mismo nivel de realización y es el aná. lisis de tales circunstancias lo que puede entregarnos, con más seguridad y mayor claridad, las bases para un juicio total y último de la obra que no sea una apreciación simplemente emotiva, sino una valoración más rigurosa, a sabiendas de que el mayor rigor intelectual perjudicará el tono cálido de la calificación emocional tan apreciable como fruto de la impresión artística que la novela, como cualquier obra de arte, debe producir.

Por lo que a composición o arquitectura se refiere, la novela de Yáñes está dividida en un Acto Preparatorio y diecisels capítulos que tienen funciones estructurales de diverso contenido y valor también variable.

El Acto Preparatorio ss una descripción del ambiente físico y moral en que se desarrollará la acción $y$, siendo tal descripción muy buena, es también muy útil no sólo por dar, desde luego, el escenario de la obra, sino porque tal ambiente es de primara importaneia y conviene que el lector lo vaya sintiendo desde antes que las vidas de los personajes le roben la atención.

Los cinco primeros capítulos están utilizados fundamentalmente para presentar personajes, vidas que luego deberán tramar sus hilos en diversos planos ele la futura accion; tambien se perfihan nutevos trazos del ambiente, se refuerzan los ya conocldos o se matizan para que el lector capte esa ric gama de ocres y grises que es el ambiente de la novela. En el segundo y tercero capitulo comienzan a revelarse algunas de esas atmas femeninas, pero siempre más en presentación que en acción, notándose a veces el émpleo de elementos redundantes o superfluos que, por serlo, deberian hiberse suprimido. In el cepitudo cunto hay vigorosos perfiles de costumbrismo y se apuntan situaciones que empiezan a forjar una de las tramas secundarias: In de Luis Pérez y Vietoria. En El Viejo Lucas Macias presenta ese matnífico personaje sin desconectarse de todo to anterior, lo que consigue mediante alusiones y toques oportunos que lo hacen un capitulo muy bien construldo; en cambio, Pascua es capítulo casi superfluo, pres su contenido, el delirio de Luis Gonzaga Pérez, podría haber quedado en el capitulo cuarto y evitar esta pausa entre el buen ca- 
pítulo preciedente y el muy bueno que sigue, Los norteños, cuya principal función es la de que, sin alterar el "clima". logrado, sirve para exponer muchas ideas de crítica moral, social y politica relativas tanto al lugar de la obra como a todo México, ideas que además del contenido que dan al libro, son determinantes de ciertas partes de la acción, de manera que puede decirse que es esto uno de los mayores aciertos del autor.

En Canicas - capítulo octavo- se robustece la trama principal en torno a Damián y Micaela y se inicia otra secundaria, la de Gabriel y. Victoria; es capítalo rico en ideas, en personajes y entambiente y, desde el aspecto estrictamente constructivo puede decirse que es aquí, en la página 175, donde empieza propiamente la novela y todo lo anterior es presentación y ubicación, es decir, preliminares. El siguiente, Victoria y Gabriel, lleva su trama en acción muy rápida y me parece un capitulo francamente defectuoso por su cambio de ritmo, y en cierto modo de enfoque, y porque el autor no pudo lograr ese efecto que parece querer intentar con la rápida sucesión alternada de elementos realistas y subconscientes que quiere conjugar ; en contraste, muy bien logrado está el manejo de lo subconsciente en el sueño del señor Cura, en el siguiente capítulo.

E1 capítulo undécimo conciurre a la acción por alusiones constantes a sucesos todavía no relatados, pero el duodécimo presenta la interferencia de una trama secundaria, la de Gabriel y Victoria, que se complica con la revelación del amor de María, dato más tarde importantísimo que el autor quiso presentar aquí súbitamente, dejándolo luego casi en el aire; es un capitulo flojo.

La desgracia de Damián Limón es la clave de la obra; el momento culminante es sugerido y aludido en muchas páginas mediante narraciones que pueden llamarse preactivas; es una manera muy hábil quẹe mantiene y acrecienta el interés y le da novedad. Resulta pertinente recordar aquí que en cierto modo es esta una técnica ya empleada por Yáñez en otra obra: aquella biografia de fray Bartolomé de las Casas (Serie Vidas Mexicanas, Eds. Xóchitl, México, 1942) que principia por la muerte y al final refiere el nacimiento del personaje; si en la biografía me parece muy discutible la conveniencia de tal sistema, en cambio el usarlo en la novela, como lo hace, con muchas modificaciones, no dudo en calificarlo de un gran acierto por la maestría con que lo domina y lo maneja y hasta el haherlo reservado para la escena culminante. (Pp. 277. y ss.)

El capítulo dócimoctuarto, Estudiantes $y$ aksentes, vuelve la atención sobre el ambiente, resuelve una de las acciones secundarias (Luis y Victo- 
ria), trata de otra (Victoria y Gabriel), iniciando una más (María y Jacobo), todo muy superficialmente, como buscando un final, lo cual es tanto más desacertado cuanto que en lo que sigue vuelve a palparse cálida y viva la íntima tragedia de dos personajes principales (Marta y María).

El último capitulo, El cometa Halley, es sin duda de gran interés pero totalmente falto de equilibrio: el ritmo se hace en extremo rápido, pues, pretendiendo referirse como' los precedentes a la vida de ese "lugar del Arzobispado", contrasta el que lo mismo haya sido contado en más de 300 páginas para el año de 1909 y luego, para todo 1910 , se ocupan 65 páginas. Claro que el novelista puede pasar ilimitadamente de épocas en espacio igualmente ilinitado, pero to que juzgo censurable es el cambio dé ritmo interno de la obra -no exigido por ninguna circunstancia interna de la misma, sino exclusivamente impuesto por el autor; por ello me parece gravemente defectuosa la primera parte de este último capítulo que, en cambio, es muy bueno en su segunda mitad.

La conclusión de esta parte del análisis es que la estructura de la obra tiene considerables fallas: casi toda su primera mitad está ocupada por una sucesión de cuadros que van presentando ambiente y personajes de gran interés, atractivo y riqueza, pero nada más; la acción principal se desarrolla en unas 120 páginas y no llega al final del libro; las acciones secundarias no se traman con la principal y por lo tanto no coadyuran a ella; en realidad hay varias tramas independierites sin más lazo común que el convivir de sus protagonistas, lo cual está de acuerdo con la intención del autor expresada en las líneas preliminares, pero un poco la desdicen la importancia de los personajes y de algunos sucesos, así como la colocación de los mismos en diversos planos, pero, sobre todo, a mi ver, lo más grave es la ya señalada falta de armonía en el ritmo de la obra; enitiéndase bien que de ninguna manera pretendo uniformidad absurda, sino adecuacion del "tempo" con la acción o con la impresión que el autor busque; siguiendo el simil musical podría decir que $A l$ filo del agua presenta el mismo defecto de la Sinfonía No 7 de Shostakovich : un desequilibrio entrella primera parte $y$ el resto de la obra.

Acaso todo esto parezca excesivo como crítica, pero a quienes interesa ver "cónio están hechas" las obras artísticas de cualquier indole, no podrian prescindir de arílisis tal, que no creo disecciớn inútil sino estudio, con peso y medida, del esqueleto o, mejor, de la arquitectura de la obra dentro de si misma: cómo funcionan las fuerzas que la componen, sus apoyos, sus descargas, 'sus ejes, sus masas y sus vanos. 
La función de la primera mitad de esta novela a que me refiero es, primordialmente, la de presentar, pintar $y$ hacer vivir los personajes $y$ el ambiente.

Muchos son los personajes, entre protagonistas y secundarios, que desfilan por exas púginas de Agustín Yáñex $y$, en conjunto, son de los elementos de la obra uno de los mejor logrados; en ella encontramos el caso, no único pero sí poco frecuente, de personajes colectivos: así, por ejemplo, los norteños, cuya individualización no se ofrece ni importa, pero que, en conjunto, integran un personaje total que tanipoco puede considerarse secundario o de fondo para que otros destaquen, como la pobre función que en el teatro lírico moderno (de la zarzuela a la ópera) se asigna al coro; sino que, muy al contrario, los norteños de Al filo del agua son como nube de tormenta que amenaza preñada de rayos hasta que uno, Damián Limón, descarga provocando el drama, tormenta contenida un tiempo pero que clarameate se ve como fuerza que empuja esa vida estática del pueblo y que, cuando logra desencadenarse, va a determinar un cambio irremisible, como en efecto sucede cuando estalla la revolución.

Personajes de primer plano son los sacerdotes: el Padre Islas, adusto y escrupuloso, alma en tensión perpetwa y tan fuerte que, al romperse un dia, resquebraja su propia envoltura corporal; el Padre Reyes, comprensivo y humano, sensato y previsor, apóstol de prudente renovación irrealizable por tanto lastre de rutina y desconfianza; ol señor Cura, tal vez el personaje mejor logrado entre los mu buenos que en la novela discurren presentado en toda la complejidad de una vida auténtica: con su bondad y su desconfianza, con su extraordinario sentido de responsabilidad que lo lleva a una severidad bien intencionada pero nefacta, con su más intima ternwara lamentablemente ahogada por un exagerado sentido del deber, una vida, en fin, consagrada minuto a minuto al bien de los demás y que, trágicamente, alcanza a ver su empeño nulificado por fuerzas enormes y extrañas, su cacrificio convertido en fracaso.

El protagonista Damián Limón, violento, pasionał, irrefrenado, individuo primario cuyo conflicto interior lo determina una lincha feros entre el desarrollo y satisfacción. de sus sentimientos, que apenas si han dejado de ser instintos, y el dure medio de represión circundante; la fuerza de este personaje reside en que, como otros pero en aspecto dictinto, representa la pugna entre un vida (en el mís lato sentido de lo biológico a lo social) y el unedio que in oprime, es uno de las casos de esa frecuente realidad en que las fmerzas extrincecas determinan el dromb individual. 
Timoteo Limón, padre de Damián, es psicológicamente más rico y complejo, no por su educación sino porque los años le han hecho superar muchos conflictos dejándole un alma seca, retorcida entre los deseos inconferados y los viejos remordimientos.

El campanero Gabriel era, de niñ, tímido, tanto que por ello fracasa en el breve ensayo de acólito a que lo obligó el señor Cura; imaginativo, reconcentrado, de gran sensibilidad, todo ello forma una personalidad de las que, al decir de "Tachas", no son de este mundo; Gabriel tampoco era de este mundo y así vivía entre tierra y cielo, en la torre tañendo las campanas; en otras condiciones hubiera tal vez cultivado con éxito algún arte, en las suyas, su lenguaje fueron las campanas. Sus pasiones están de acuerdo con su temperamento. Es un personaje lleno de posibilidades, de gran riqueza psicológica y cuidadosamente, amorosamente construído: lo vemos

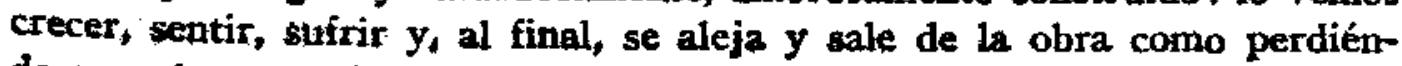
dose en la penumbra, en una oscuridad análoga a la de su procedencia.

Las mujeres, esas mujeres enlutadas, son en conjunto $y$ algunas individualmente, personajes también de primera lípea, tanto por su función como por la maestría que las presenta y las anima del principio al fin de la obra, de tal manera que casi por si solas formen al ambiente, el chima moral y social de la novela.

Destecan, entre todas, Micaela, Marte y Marís. Tal ves alguien piente que en esta enumeracion primordial debería figurar Victoria, pero no quiero ahora referime a la importancie funcional de los personajes, sino 2 su valor en cuato a tales, es decir, ou interes en si mismos y la pleaitud con que el autor alcantó \& realicar eoos ceracteres; por ello, aunque Victoria es protagonista y carácter bien realiodo, pertenece a un tipo a mi juicio mis divisigado $y$ frecuente, menos original.

Micola es una majer ain compliomcioses, es un sucillo caso de fuerte sexusidad gue busea satiofacerse pero que comprimida, no reprimida psicológicanente-, par al tnedio, choca con él; lo aimilitud con el caso de Damisn Limón es evidente y en dos vichs tan paraleles, pero de signo opruesta, la putua atracción debí duras, besistencias que se interponen

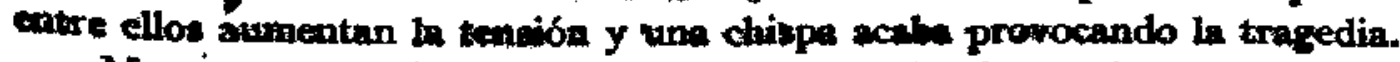

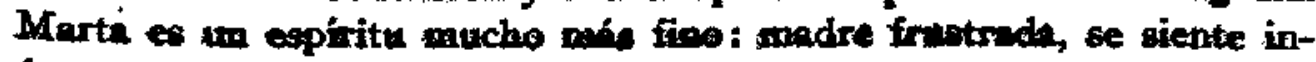

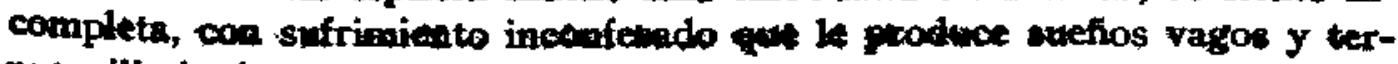
nate ilimitada, por eso es "Marta del baen oonojo", pasiva, resignada y triste.

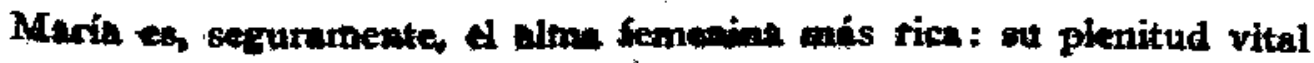
y el temperamento extravertido en contraste con $\alpha$ medio que la rodea, y 
su condición de huérfana, le producen más graves inhibiciones, asi sus contrastes son mayores y la presión interior va aumentando con los afios, hasta encontrar un escape sin medir consecuencias.

Todos ellos son personajes auténticos, vidas humanas, no manequíes ni títeres, y no hay hilos que los mtevan ni voz ajena detrás de la cortina; tienen, por el contrario, verdadera realización vital y se revelan principalmente por acción y diálogos coherentes con sus respectivas personalidades.

Lucas Macías es un viejo apologista y algo zahorí que habla de lo contemporáneo en parábolas de referencias históricas, con temas apropiados y casi- transparentes pero nunca directos; observador agudo, stus deducciones parecen profecías.

El viejo Lucas Macías es tipo más que carácter, no interviene propiamente en ninguna trama pero su presencia es de gran peso en la obra únicamente por su presencia misma que equilibra y coordina muchas cosas. No soporta la estructura de la obra que, seguramente, podría existir sin él, pero sin embargo su sentido funcional es concreto y evidente. Pienso en algunas obras pictóricas que acaso ayuden a aclarar esta idea: así, por ejemplo, la cabeza de toro en el ángulo superior izquierdo del Guernica de Picasso, figura que; en lo dinámico, sirve de meta a la diagonal ascendente que es uno de los soportes del cuadro, en lo estático ayuda al equifibrio de las masas en la parte superior $y$, por último, es simbolo importante en la idea que la obra contiene; otro ejemplo puede darse en el cuerpo yacente a los pies de Cortés y la Malinche, en el fresco de Orozco (escalera de la Escuela Nacional Preparatoria), que forma una base horizontal sólida y proporcionada para que descansen las otras dos masas de las figuras sedentes," las une como una trabe que soporta dos recias columnas $y$ tiene también un. sentido fuerte $y$ evidente como signo del abatimiento, la postración, la derrota del pueblo vencido sobre el cual se levantó y reposa aquella unión que fue y es nuestro mestizaje esencial.

- Ese Lucas Macías, a mi juicio, es un tipo magistral en sí y por esa sutil función que tiene en la obra, que tal vez nunca se proyectó así -al menos en todo su alcance- deliberadamente y a priori por el autor, sino que pertenece por completo a la fuerza de la intuición que por modos tan misteriosos e inexplicables conduce muchas veces al artista que verdaderamente lo es, al hallazgo de la figura, el color, la línea, la nasa o la modulación, según el arte de que se trate, que sin causa de estricta lógica constructiva era, sin embargo, indispensable para el funcionamiento del todo en el grado, matiz; ambiente o tonalidad que el autor necesitaba para el efecto general buscado. 
Naturalmente no todos los personajes tienen tanto valor; otros discurren en planos de fondo $y$ algunos, debe decirse, salieron un tanto fallidos porque crean situaciones de cierta importancia y después se amenguan y desvanecen sin motivo ni causa suficiente: así Leonardo Tovar y un poco Merceditas Toledo. Pero no se trata aquí de intentar un análisis exhaustivo de todos los personajes que pasan y repasan por las callejas de ese "lugar del Arzobispado", pues los citados - para mí los mejores-, bastan para el objeto que estas notas persiguen y que no es, de ninguna manera, presentar resumen ni sinopsis del libro de Agustín Yáñez, sino apuntar los valores que ahí encuentro, asi como la ubicación de los mismos.

La religión y el amor son las dos grandes fuerzas que juegan en toda la novela, no por modo uniforme sino antes en gama muy vasta según la propia escala de cada una de esas vidas que alli transcurren, sobre el tono de fondo de un fatalismo que oscila entre la indiferencia resignada y los más agudos pesimismos y un sentimiento del honor, de clara raíz española, opresor y hasta cruel, sin grandeza ni elevación, hosco, vulgar y zafio; con todo lo cual, el conjunto de los sentimientos que en el libro concurren es de sabor amargo y de dibujo austero; por eso mismo se avivan y chisporrotean con mayor brillo y estallan con más o menos fuerza las trayectorias de pasiones en verdad comunes y ordinarias, que en otro medio resultarian acaso pobres, pero que ahí parecen líneas de fuego en el aire oscuro de esas almas enlutadas; clima afectivo y trayectorias pasionales de trazo fuerte, con gran habilidad de dibujo y color: todo ello un acierto más, sobre el nada pequeño de los personajes, que nos presenta $\mathrm{Al}$ filo del agua.

Las ideas, los conceptos, giran en torno a los sentimientos y a las costumbres. Lo establecido y tradicional se equipara al orden y al deber, a lo que está bien y así debe seguir aunque se palpen los defectos del sistema ; toda innoyación y en general toda idea viva produce escándalo y animadversión, desde el apostolado del Padre Reyes hasta los juicios de los norteños. La ideas de una y otra parte, la capacidad intelectiva y el medio cultural son coherentes con las otras manifestaciones de la vida del lugar, es decir, hay unidad - no uniformidad- y coordinación entre los caracteres y el papel de cada uno en la acción de la obra.

A mi juicio, el mayor acierto logrado por Agustín Yáñez en $A l$ filo del agua es el ambiente. Si viven los personajes, más vive el ambiente en que se mueven: el color y el dibujo del paisaje reseco, las calles quietas, las casas austeras y las cruces presidiendo todo; los ruidos del pueblo es- 
tán tratados con gran atingencia: ladridos en la noche, pisadas de caballos en los empedrados, cantos piadosos y las campanas, las campanas que rigen la vida individual y colectiva y que son, no portavoz, sino la voz misma del pueblo en el repique de la fiesta y en el doblar por los difuntos. Ambientes como el de ese "lugar del Arzobispado" en aquel año de 1909, pueden parecer absurdos; esa vida de esos pueblos creeríase falsa por inexistente; vista desde acá, desde México y en estos días, aquel ambiente parece, aparece, intensamente agobiador, asfixiante, lúgubre; pero el juicio no debe ser precipitado ni superficial, debe, partirse de que el vivir en ambientes distintos requiere medirse con unidades diversas, como el módulo que armoniza la portada románica es otro del que genera la fachada gótica. Aquellos pueblos vistos por dentro, compartiendo su vida diaria son austeros, tal vez rigidos; el orden constriñe pero no asfixia; la rutina fastidia pero no duele; el orden está regido por campanas, y i qué dieran todos los pueblos por tener aquellas campanas y aquel Gabriel de campanero 1; la rutina es, en parte, tradíción, y en ese tanto se la respeta y se la aprecia y defiende, con un amor distante $y$ seco como el que se guarda a la memoria y al nombre de los antepasados que no conocimos pero que sentimos como parte nuestra; el ambiente recoleto sólo exaspera transitoriamente y más bien adormece; pasados los momentos de prueba como la adolescencia, un amor frustrado, un gran deseo fallido, la vida vuelve a su lento deslizarse como agua en canal. Los pueblos, nuestros pueblos mexicanos, al menos los de la meseta, los de "tierra adentro", lo mismo los "alteños" de Agustín Yáñez que los "abajeños" de mi tierra, han sido asi $y$, aunque cada vez lo son menos, mucho queda para juzgar de la exactitud y realidad de ambiente en las páginas de $A l$ filo del agua.

$Y$, sin embargo, la novela de Yáñez no es realista en el exacto sentido literario del término; en tal acepeión mucho más realismo se encuentra, por ejemplo, en Rubén Romero, pero mucha menos calidad también. La

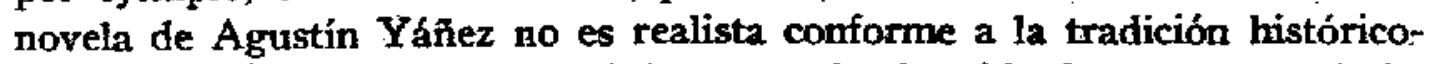
literaria, porque no retrata, ni lo pretende, la vida integra y total del pueblo, sino que de ella abstrae y selecciona los elemeatos que le importaa, sin afirmar ni negar los demás que haya o pueda haber, sino únicamente dejándolos fuera del campo visual de su enfoque; es decir, Yáñez hace realismo, sólo que con un sentido artistico de realidad más depurado; si se que quieren ejemplos, puedo decir que el realismo de López Portillo y Rojas es el de los paisajes de José María Velasco, mientras que en Yánez ese "lugar del Arzobispado" es una realidad en mismo seatido que la Pradera de San Isidro de Goya o la Viste de Toledo de El Greco. 
En cuanto al estilo, decir que es muy bueno casi resulta superfluo, porque hace veinte años la prosa de Yáñez es, por muchos conceptos, magnífica. Ahora, en las páginas de $A l$ filo del agua, son muy pocos los defectos que se pueden hallar: uno que otro error de sintaxis que se deslizó, algunas formas cultas de lenguaje que disuenan en diálogos de carácter familiar y popular, etc., pero mucho más pesa el otro platillo, el de las descripciones precisas, llenas de color y relieve, de los diálogos enérgicos, de las narraciones jugosas, de los recursos tan acertados como aquellos trozos del oficio del Viernes Santo incrustados en el delirio de Luis Gonzaga Pérez y aquello otro, ya mencionado, de aludir a sucesos que aún son futuros en el desenvolverse de la acción.

Todo lo anterior tiende a probar que, según dije páginas atrás, $A l$ filo del agua es novela auténtica y buena; sus principales valores están en el tratamiento del ambiente, en el estilo y en la realización de los personajes. Dije también que estas notas no pretenden tener ningún sentido ni objeto de comparaciones que, más que otras cosas, deben hacerse bien o no hacerse; además, hay otros motivos que vuelven inoportuno tratar de asignarle a Agustín Yáñez un sitio prenumerado en cualquier arbitrario escalafón, tratándose de un escritor no prematuro pero cuya plena y cuajada madurez está en fecunda producción, uno de cuyos frutos es esta vigorosa, austera $y$ honda novela.

Hemos visto los varios elementos que construyen la novela de Yáñez; antes de concluir, sólo falta una referencia que juzgo ineludible a un elemento extraliterario, que en el caso presente merecería llamarse "paraliterario", si el vocablo no fuese tan híbrido e ingrato. Quiero referirme a las ilustraciones que adornan esta primera edición de $A l$ filo del agua; una para cada capitulo -dieciséis en total-, más la portada, las capitulares $y$ viñetas, son los grabados de Julio Prieto.

Muchos de esos grabados son de superior calidad, así la portada, los magníficos ylel Sueño y la Casa de Ejercicios, el del norteño, el que corresponde al capítulo "Canicas", el de la escena culminante del libro: el asesinato de Micaela y el t́ltimo, el de la entrada de los revolucionarios, y no son sin duda los únicos; buenas son también las capitulares y las viñetas, entre las que destaca la viñeta puesta al fin de la novela: esas siluetas de hombres a caballo que se alejan, a la vera de un árbol en cruz, torcido y reseco, viejo y estéril. 
Pero esos buenos grabados tienen en el libro una función: ilustrar el texto, y es ahi donde surge el problema que se subdivide en múltiples fases pero que, en rigor, puede plantearse como un pro y contra de las ilustraciones a textos estrictamente literarios.

Alfonso Reyes en El Deslinde, ese libro por tantos conceptos admirable, dice en la página 14: "De Sancho Panza se nos hace saber que también se lo llamó Sancho Zancas, porque tenía 'la barriga grande, el talle corto y las zancas largas' ( $Q u i j .$, I, IX). Pero ello es que los héroes de Cervantes han pasado a la imaginación popular segtun los interpretó la pluma de Gustave Doré. $Y$ sea ello que éste no encontró modo de armonizar los rasgos que se le proponian, o sea que, inconscientemente, la panza voluminosa de Sancho lo impresionó más que las zancas largas (y la gran panza parece exigir piernas cortas y gordas), dibujó al escudero como hoy lo recuerdan todos: rechoncho, de tronco corpulento, de baja estatura y piernas repletas, en contraste con la enjuta esbeltez de su amo, como una ' $o$ ' junto a una ' $l$ '. Cierta economía mnemónica ha hecho prevalecer este tipo sobre el descrito realmente por Cervantes."

Lo ocurrido con Don Quijote y Sancho se repite con gran frecuencia, porque si la descripción de un carácter resultará siempre más fácil y vívida al escritor que al pintor, en cambio en la descripción física el artista plástico tiene recursos de que el escritor carece, pues, por mucha fuerza y colorido que en sus frases ponga, no alcanzará la intensidad y precisión de unos rasgos, si se quiere sugerir una imagen visual.

Muy fácil es que el dibujante o grabador altere la intención del escritor y traicione, en cierto modo, el texto que pretende servir, porque al fin $y$ al cabo cada uno tendrá siempre su punto de vista y su propia imaginación $y$, en resumen, la cuestión de los aciertos o errores de los textos ilustrados es un aspecto de otro vasto problema: el de la posibilidad y la conveniencia de buscar o intentar la colaboración de artes diversas entre sí.

En este caso presente creo que la colaboración, como tal, no ha sido feliz en todas las ilustraciones, pues algunas de ellas no coinciden con la sugestión rigurosa del texto; ello, naturalmente, sin menoscabo alguno de la calidad magnífica de los grabados, con los cuales Julio Prieto confirma y reafirma el justo prestigio que en su arte ha conseguido.

Como punto final a estas notas, una vez más repito que de ninguna manera se ha perseguido la comparación entre las tres novelas que he pretendido anotar, ni he querido mostrar ejemplos sino apuntar valores. Porque 
un ejemplo significa, de por sí, una meta, un ideal, un modelo. $Y$ ¿cuál sería el modelo de la novela contemporánea? ¿hay, siquiera, una idea precisa de lo que la novela debe ser y de lo que no debe ser? Por mi parte, no creo que exista ni convenga fijar una "novela tipo", que en arte y literatura es bien sabido cuán rápidamente al modelo decae y se convierte en molde, señal inequivoca de que un estilo, modalidad o género, ha muerto y trata de conservarse embalsamado en las recetas prefijadas.

Roger Caillois, en un estudio muy sugerente, aunque de perceptible desigualdad, 1 ya discutido por José Luis Martínez, ${ }^{2}$ afirma que la novela no tiene ni puede tener reglas. Ciertamente es asi, pero ello no impide que la novela, como toda obra, esté sujeta a condiciones técnicas que pueden ser descubiertas, conocidas, analizadas y valoradas.

Como un edificio, como un cuadro, como una sinfonía, la novela está hecha de algún modo; encontrar ese modo, ese módulo, es lo que he pretendido hacer respecto a las novelas a que estas notas se refieren; si lo mismo se hace con otras más, antiguas y modernas, podremos saber con claridad qué valores literarios contienen y cómo están realizados en la novelística mexicana.

En el estudio precitado, Roger Caillois señala como función y sentido fundamental de la novela contemporánea el servir de evasión al lector, de lo cual deriva la popularidad y auge de este género literario hoy tan prolifico y desarrollado.

Aunque no una sino varias observaciones han de hacerse a la tesis de Caillois - y alguna vez espero volver sobre el tema que ahora toco en forma meramente tangencial-, parece indudable que en lo principal acierta $y$ que, en verdad, la novela es puerta de escape, vía de fuga para un yo insatisfecho $y$ atormentado por cualesquiera de las muchas causas que concurren a esa insatisfacción, ordinario fenómeno de nuestra época. Caillois insiste, particularmente, en que tal deseo de evasión es una huída del hombre en lucha con la sociedad, llegando a decir que "no hay más que un único tema de novela: la existencia del hombre en la sociedad y su conciencia de las servidumbres impuestas por el carácter social de esa existencia" y, páginas adelante, "el hombre no se interesa ya sino por sí mismo, en sus tremendas desgracias o su malestar indefinible". a

1 Rocrs Camlors. Sociología de la novela. Ed Sur, Buenos Aires, 1942.

2 Nota en "El Hijo Pródigo", núm. 3, Méxioo, junio de 1943, p. 189.

3 Cannors. Op. ciț., págs. 34 y 38. 
Aceptando, por lo pronto, tales proposiciones; ocurre desde luego que la evasión puede buscarse por dos vías : una que puede llamarse exterior y que produciria o explicaría la novela de acción: de viajes, de ambiente exótico, de aventuras, policial, etc.; y otra vía que es preciso denominat interna, la cual lleva a la novela psicológica hasta el surrealismo y el psicoanálisis. También puede ocurrir que, al ménos en ciertos casos, se busque en la novela, no tanto una evasión cuanto turià catarsis más o menos éncubierta, peró vuelvo a decir que por ahora no hagorsino señalar puntos que requieren más amplio estudio y confrontaciones cuidadosas con sus posibles realizaciones literales.

Novela de caracteres; novela de ambiente; novela de introspección, de imaginación y de estados subconscientes; peeden todas ser caminos de huida, evasiones de un yo insatisfecho que busca otras vidas, otros paisajes y otros planos de sí mismo; y acaso esto áltimo sea lo mejor y más efectivo por muchos conceptos.

Tales especies se dan en la novela mexicana contemporánea, a más de otras que posteriorès anotaciones señalarán.

He creído útil anotar tales puntos para quienes interese el estudio del género novela, a sabiendas de su reconocida debilidad e inmadurez en México como en toda Iberoamérica. 